\title{
Sobressemeadura de soja com Urochloa ruziziensis e a cultura do milho em rotação
}

\author{
Núbia Maria Correia e Leonardo José Petean Gomes
}

\begin{abstract}
(1)Embrapa Hortaliças, Rodovia BR-060, Km 09, Caixa Postal 218, CEP 70351-970 Brasília, DF, Brasil. E-mail: nubia.correia@embrapa.br (2)Universidade Estadual Paulista Júlio de Mesquita Filho, Campus de Jaboticabal, SP, Brasil. E-mail: leo_pgomes@hotmail.com
\end{abstract}

\begin{abstract}
Resumo - O objetivo deste trabalho foi avaliar a sobressemeadura de soja com Urochloa ruziziensis, quanto à capacidade de produção de matéria seca pela forrageira, à infestação de plantas daninhas e ao desenvolvimento da cultura do milho em rotação, no sistema plantio direto. O experimento foi desenvolvido em delineamento de blocos ao acaso, com quatro repetições, em arranjo fatorial 2 × $5+1$. Avaliou-se a sobressemeadura com U. ruziziensis, em dois estádios de desenvolvimento da soja $\left(\mathrm{R}_{6}\right.$ e $\left.\mathrm{R}_{8}\right)$ e cinco quantidades de sementes: 200 , 400, 600, 800 e 1.000 pontos de valor cultural (PVC). Como testemunha, manteve-se um tratamento sem sobressemeadura. A sobressemeadura de 200 PVC de $U$. ruziziensis, nos estádios $\mathrm{R}_{6}$ ou $\mathrm{R}_{8}$ da soja, resulta na formação de palha em quantidade suficiente para o sistema plantio direto, além de beneficiar o controle de plantas daninhas na cultura do milho em rotação. Porém, em quantidade elevada, a palha de U. ruziziensis sobre o solo afeta a altura e a produção de grãos de milho.
\end{abstract}

Termos para indexação: Brachiaria ruziziensis, Glycine max, Zea mays, comunidade infestante, integração lavoura-pecuária, plantio direto.

\section{Soybean oversowing with Urochloa ruziziensis and corn as rotation crop}

\begin{abstract}
The objective of this work was to evaluate soybean oversowing with Urochloa ruziziensis, for the soybean capacity of dry mass production, for weed infestation, and corn crop development under no-tillage system. The experiment was carried out in a randomized complete block design, with four replicates, in a $2 \times 5+1$ factorial arrangement. Oversowing with $U$. ruziziensis was evaluated in two soybean growth stages $\left(\mathrm{R}_{6}\right.$ and $\left.\mathrm{R}_{8}\right)$ and five seed quantities: $200,400,600,800$, and 1,000 points of cultural value (PCV). For control, a treatment without oversowing was kept. Oversowing of 200 PCV of $U$. ruziziensis, at the $\mathrm{R}_{6}$ or $\mathrm{R}_{8}$ soybean stages, results in a sufficient straw quantity for no-tillage system, and favors weed control in the rotation corn crop. However, in high amounts, U. ruziziensis straw over the soil affects corn plant height and grain production.
\end{abstract}

Index terms: Brachiaria ruziziensis, Glycine max, Zea mays, weed, crop-livestock interaction, no-tillage.

\section{Introdução}

A maior limitação para a sustentabilidade do sistema plantio direto(SPD), na regiãonordeste do Estado de São Paulo e no Centro-Oeste do Brasil, é a baixa produção de palha no período outono-inverno-primavera, em razão das condições climáticas desfavoráveis e da baixa disponibilidade hídrica, caracterizadas pelo inverno seco. Consequentemente, muitos locais, nessas regiões, ficam ociosos durante sete meses do ano e com baixa cobertura vegetal (Barducci et al., 2009). Uma das opções para amenizar esse problema é a utilização do sistema de integração lavoura-pecuária. Porém, no verão, a maior parte dessas áreas é ocupada com soja, que apresenta baixa relação $\mathrm{C} / \mathrm{N}$ e não tem o mesmo desempenho que o milho em consórcio com plantas de cobertura (Kluthcouski \& Aidar, 2003; Silva et al., 2006).

A sobressemeadura de plantas de cobertura nos estádios $\mathrm{R}_{5}$ a $\mathrm{R}_{7}$ da soja tem sido difundida como alternativa à formação de palha em sucessão à cultura da soja (Pacheco et al., 2008; Pacheco et al., 2013; Silva et al., 2013). Nesse contexto, tem-se a região nordeste do Estado de São Paulo que apresenta dificuldade para o estabelecimento de culturas no outono-inverno, devido à escassez hídrica, interferindo na formação de palha para o sistema de plantio direto.

O sucesso dessa tecnologia depende dos seguintes fatores: condições meteorológicas, principalmente precipitação, da véspera da semeadura até dez dias 
depois da emergência; da capacidade de germinação e crescimento da planta de cobertura em superfície; do grau de desfolhamento da cultura; e da incidência direta de luz sobre a superfície do solo (Pacheco et al., 2008; Pacheco et al., 2013). Para a consolidação da sobressemeadura, é necessário que se avaliem e selecionem espécies com boa adaptação ao cultivo consorciado, não prejudiquem a cultura principal, sejam tolerantes à deficiência hídrica, produzam elevada quantidade de massa para cobertura do solo e, se possível, que apresentem aptidão para forragem (Lara-Cabezas, 2004; Perin et al., 2004; Pacheco et al., 2008).

Os benefícios da sobressemeadura da cultura da soja com $U$. ruziziensis são inúmeros e incontestáveis, seja na formação de palha para o sistema plantio direto, seja no estabelecimento de pastagens e oferta de alimento ao gado na época seca do ano. Entretanto, algumas dúvidas são pertinentes e precisam ser esclarecidas, como a quantidade ideal de sementes e o estádio fenológico da soja no momento da semeadura. A quantidade de sementes deve ser ajustada para cada espécie de cobertura e estipulada em razão de seu valor cultural.

O objetivo deste trabalho foi avaliar a sobressemeadura de soja com Urochloa ruziziensis, quanto à capacidade de produção de matéria seca pela forrageira, à infestação de plantas daninhas e ao desenvolvimento da cultura do milho em rotação, no sistema plantio direto.

\section{Material e Métodos}

O experimento foi desenvolvido em campo, de outubro de 2011 a maio de 2013, na área experimental da Unesp, Campus de Jaboticabal, SP, situada à altitude de $575 \mathrm{~m}$, a $21^{\circ} 15^{\prime} 24^{\prime \prime} \mathrm{S}$ e $48^{\circ} 16^{\prime} 41^{\prime \prime W}$. Segundo a classificação de Köppen, o clima da região é do tipo $\mathrm{Aw}$ - tropical com inverno seco (Miranda et al., 2015). Os totais mensais de precipitação e as médias mensais de temperatura mínima e máxima, durante o período experimental, estão apresentados na Figura $1 \mathrm{~A}$.

O solo da área experimental é representativo da região, classificado como Latossolo Vermelho-Escuro, de textura argilosa, com $442 \mathrm{~g} \mathrm{~kg}^{-1}$ de argila, $96 \mathrm{~g} \mathrm{~kg}^{-1} \mathrm{de}$ silte e $462 \mathrm{~g} \mathrm{~kg}^{-1}$ de areia; sua análise química apresentou: $\mathrm{pH}$ em água, 6,0; CTC, $\mathrm{H}+\mathrm{Al}, \mathrm{Ca}, \mathrm{Mg}$ e
$\mathrm{K}$ de $71,19,31,17$ e 3,5 mmolc $\mathrm{dm}^{-3}$, respectivamente; matéria orgânica, $18 \mathrm{~g} \mathrm{dm}^{-3}$; e P, $44 \mathrm{mg} \mathrm{dm}^{-3}$.

$\mathrm{O}$ experimento apresentou duas fases. Na primeira, iniciada em outubro de 2011 e término em outubro de 2012, a cultura da soja foi instalada, com posterior sobressemeadura com $U$. ruziziensis e a avaliação do desenvolvimento da forrageira no período outono/ inverno (entressafra). Na etapa seguinte, novembro de 2012 a maio de 2013, foram estudados os efeitos do cultivo da espécie forrageira sobre a cultura do milho em rotação e sobre as plantas daninhas da área experimental.

A soja 'Dow 5 D 660 RR' foi semeada em 27/10/2011, em sistema plantio direto, à profundidade de $5 \mathrm{~cm}$, com $0,45 \mathrm{~m}$ de distância entre as linhas e 21 sementes por metro. A adubação consistiu da aplicação de $300 \mathrm{~kg} \mathrm{ha}^{-1}$ da fórmula $\mathrm{N}-\mathrm{P}_{2} \mathrm{O}_{5}-\mathrm{K}_{2} \mathrm{O}$ 02-20-20. Ao sulco de semeadura, também se aplicaram inoculante líquido $(0,24 \mathrm{~L}$ do produto comercial por hectare) e o inseticida clorpirifós $\left(0,48 \mathrm{~kg}\right.$ i.a. $\left.\mathrm{ha}^{-1}\right)$.

As parcelas mediram $4,05 \mathrm{~m}$ de largura e $7 \mathrm{~m}$ de comprimento, com 7 linhas centrais e $6 \mathrm{~m}$ de comprimento como área útil, que totalizaram $18,9 \mathrm{~m}^{2}$.

Para o controle de plantas daninhas, aplicaramse os herbicidas glifosato (a 1,0 kg e.a. ha ${ }^{-1}$ ) e fluazifop-p-butyl $\left(0,25 \mathrm{~kg} \mathrm{ha}^{-1}\right)$ aos 29 dias após a semeadura (DAS).

Quando as plantas de soja estavam nos estádios de desenvolvimento $\mathrm{R}_{6}$ (vagens com granação de $100 \%$ e folhas verdes) e $\mathrm{R}_{8}$ (início a $50 \%$ de desfolha), nos dias 10 e 23/2/2012, respectivamente, foi feita a semeadura manual, a lanço, da espécie forrageira, com base nas quantidades de sementes a serem testadas. A ocorrência de chuva no período de 20/1 a 10/3/2012 pode ser observada na Figura $1 \mathrm{~B}$.

Utilizaram-se sementes peletizadas de $U$.ruziziensis, que apresentavam $81,0 \%$ de germinação, 96,0\% de pureza e valor cultural de 77,76. Como a quantidade de sementes $\left(\mathrm{kg} \mathrm{ha}^{-1}\right)$ é a relação entre o PVC desejado e o valor cultural das sementes, empregaram-se 2,57, $5,14,7,71,10,28$ e $12,85 \mathrm{~kg} \mathrm{ha}^{-1}$ de sementes para, respectivamente, 200, 400, 600, 800 e 1.000 PVC.

Os grãos de soja foram colhidos mecanicamente em 10/3/2012, aos 29 e 16 dias após a sobressemeadura (DAS) nos estádios $\mathrm{R}_{6}$ e $\mathrm{R}_{8}$, respectivamente. A altura do corte das plantas de soja foi de 8 a $10 \mathrm{~cm}$ da superfície do solo. 
$\mathrm{O}$ estande das plantas forrageiras foi quantificado aos $15\left(25 / 2\right.$ e 9/3) e aos 35 (16/3 e 29/3) DAS em $R_{6}$ e $\mathrm{R}_{8}$. Contou-se o número de plantas em uma área de $5,4 \mathrm{~m}^{2}$, correspondente a $0,9 \mathrm{~m}$ de largura e $6 \mathrm{~m}$ de comprimento, amostrada dentro da área útil da parcela.

Aos 60 e aos 233 dias após a colheita (DAC) da soja, avaliou-se visualmente a cobertura do terreno pelas plantas forrageiras, por meio da escala de notas de 0 a $100 \%$, em que zero representa a ausência de plantas e 100 a cobertura total da área pelas forrageiras. Aos 233 DAC, coletou-se a parte aérea das plantas de duas áreas de $0,45 \mathrm{~m}^{2}$, amostradas aleatoriamente dentro da área útil de cada subparcela, para determinação da massa de matéria seca da parte aérea das plantas. Aos
233 DAC, também se realizou a avaliação visual de infestação pelas plantas daninhas, por meio de escala de notas em percentagem (de 0 a 100\%).

Aos 40 e aos 15 dias antes da semeadura do milho, as plantas daninhas e as forrageiras presentes na área experimental foram dessecadas com $1,44 \mathrm{~kg}$ e.a. ha ${ }^{-1}$ de glifosato, na primeira aplicação, e 1,08 kg i.a. ha-1, na segunda.

O híbrido de milho Maximus TLTG Viptera foi semeado em 11/12/2012, em sistema plantio direto, à profundidade de $5 \mathrm{~cm}$, com $0,90 \mathrm{~m}$ de distância entre as linhas e 5,4 sementes por metro. A adubação consistiu da aplicação de $350 \mathrm{~kg} \mathrm{ha-1}$ de N- $\mathrm{P}_{2} \mathrm{O}_{5}-\mathrm{K}_{2} \mathrm{O}$ 04-20-20
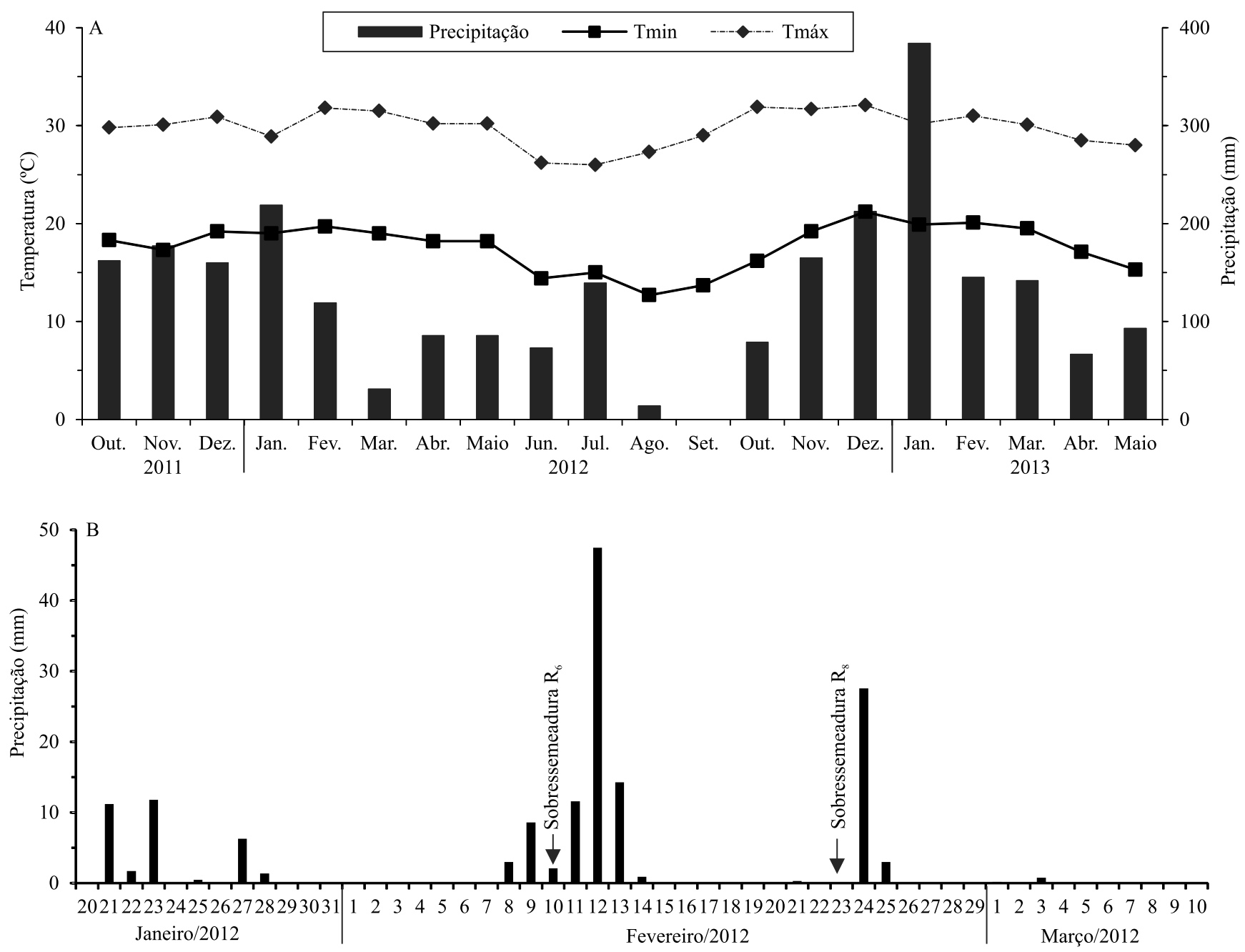

Figura 1. Valores de precipitação mensal e de temperaturas médias mínimas e máximas mensais (A), no período de outubro de 2011 a maio de 2013 e valores diários de precipitação (B), registrados de 20/1 a 10/3/2012. Fonte: Estação Agroclimatológica do Departamento de Ciências Exatas da FCAV/Unesp, localizada a 2,0 km da área experimental (ESTAÇÃO..., 2015). 
ao sulco de semeadura, e as sementes adquiridas já estavam tratadas com inseticida e fungicida.

$\mathrm{O}$ experimento foi instalado seguindo-se a mesma disposição das parcelas do experimento do ano agrícola anterior. As parcelas constituíram-se de 4,05 m de largura e $7 \mathrm{~m}$ de comprimento, com 2 linhas centrais e $5 \mathrm{~m}$ de comprimento como área útil, que totalizaram $10,8 \mathrm{~m}^{2}$.

Aos 29 dias após a semeadura, o milho recebeu adubação nitrogenada em cobertura, com $75 \mathrm{~kg} \mathrm{ha}^{-1}$ de $\mathrm{N}$ na forma de ureia. No mesmo dia, os herbicidas glifosato $\left(1,2 \mathrm{~kg}\right.$ e.a. ha- $\left.{ }^{-1}\right)$ e atrazine $\left(1,0 \mathrm{~kg}\right.$ i.a. ha $\left.{ }^{-1}\right)$ foram pulverizados. As plantas de milho tinham a quarta folha totalmente desenvolvida, e as plantas daninhas de 2 a 10 folhas definitivas (para as eudicotiledôneas) e até 4 perfilhos (para as gramíneas).

Antes da aplicação dos herbicidas, contou-se o número de plantas daninhas em duas áreas de $0,225 \mathrm{~m}^{2}$, escolhidas aleatoriamente dentro da área útil da parcela, que tiveram a parte aérea coletada e levada para secagem em estufa até a obtenção de massa constante.

O estande das plantas de milho foi avaliado aos $23 \mathrm{e}$ 122 dias após a semeadura, por meio da contagem do número de plantas na área útil das parcelas. A altura das plantas foi determinada aos 66 dias após a semeadura, tendo-se considerado a distância entre a base da planta e a extremidade do colmo de dez plantas da área útil da parcela.

Aos 64 dias após a semeadura, no estádio de florescimento e polinização $\left(\mathrm{R}_{1}\right)$, determinaram-se os teores foliares de $\mathrm{N}, \mathrm{P}, \mathrm{K}, \mathrm{Ca}, \mathrm{Mg}, \mathrm{S}, \mathrm{B}, \mathrm{Cu}, \mathrm{Fe}, \mathrm{Mn}$ e $\mathrm{Zn}$. Coletou-se a primeira folha, abaixo da espiga, de dez plantas escolhidas aleatoriamente dentro da área útil de cada parcela. $\mathrm{O}$ material foi analisado por meio de extração via seca, exceto o $\mathrm{N}$ que foi analisado pelo método de Kjeldahl.

Para a obtenção da produtividade de grãos de milho por parcela (aos 135 dias após a semeadura), colheramse manualmente as espigas da área útil de cada parcela, que foram posteriormente debulhadas, e corrigiu-se para 13,0\% a umidade dos grãos. As espigas também foram contadas para estimativa de seu número por hectare.

O delineamento experimental foi o de blocos ao acaso com quatro repetições, em arranjo fatorial $2 \times 5+1$. Avaliou-se a sobressemeadura com $U$. ruziziensis, em dois estádios de desenvolvimento da soja $\left(\mathrm{R}_{6}\right.$ e $\left.\mathrm{R}_{8}\right)$ e cinco quantidades de sementes (200, $400,600,800$ e 1.000 PVC). Como controle, mantevese um tratamento sem sobressemeadura com a espécie forrageira.

Os resultados obtidos foram submetidos ao teste $\mathrm{F}$ da análise de variância. Os efeitos das épocas de sobressemeadura, quando significativos, foram comparados pelo teste de Tukey, a 5\% de probabilidade, e os efeitos das quantidades de sementes, por ajuste polinomial dos dados. As interações, quando significativas, foram desdobradas, $\mathrm{e}$ as médias comparadas pelo teste de Tukey, a 5\% de probabilidade, para épocas de sobressemeadura, e por ajuste polinomial dos dados, para quantidades de sementes. Para avaliar o comportamento da testemunha sem sobressemeadura, em relação às épocas de sobressemeadura e quantidades de sementes, os graus de liberdade de tratamentos foram desdobrados segundo um esquema de contrastes ortogonais de interesse. A testemunha foi comparada aos tratamentos convenientes. Aplicou-se o teste F para cada contraste, tendo-se aceitado ou rejeitado a hipótese $\mathrm{H}_{0}(\mathrm{Y}=0)$.

\section{Resultados e Discussão}

Houve efeito significativo das quantidades de sementes de $U$. ruziziensis sobre a densidade de plantas, aos 15 e 35 DAS, e sobre a cobertura do terreno pelas plantas aos 60 e 233 DAC (Tabela 1). Os estádios de desenvolvimento da soja influenciaram significativamente a densidade de plantas aos 15 DAS e a percentagem de cobertura do terreno pelas plantas

Tabela 1. Resultados do teste $\mathrm{F}$ da análise de variância, para a densidade de plantas de Urochloa ruziziensis, aos 15 e 35 dias após a sobressemeadura (DAS) da cultura da soja, além da cobertura do terreno pela forrageira, aos 60 e 233 dias após a colheita (DAC) da soja, e matéria seca (MS) das plantas aos 233 DAC.

\begin{tabular}{|c|c|c|c|c|c|}
\hline \multirow{2}{*}{$\begin{array}{l}\text { Fontes de } \\
\text { variação }\end{array}$} & \multicolumn{2}{|c|}{ Densidade de plantas } & \multicolumn{2}{|c|}{ Cobertura } & \multirow{2}{*}{$\begin{array}{c}\text { MS } \\
233 \mathrm{DAC}\end{array}$} \\
\hline & $15 \mathrm{DAS}$ & $35 \mathrm{DAS}$ & $60 \mathrm{DAC}$ & $233 \mathrm{DAC}$ & \\
\hline$\overline{\mathrm{QS}^{(1)}}$ & $32,82^{* *}$ & $32,88^{* *}$ & $40,89 * *$ & $12,42 * *$ & 2,00 \\
\hline $\mathrm{ED}^{(2)}\left(\mathrm{R}_{6}\right.$ e $\left.\mathrm{R}_{8}\right)$ & $210,04^{* *}$ & 2,15 & $30,11^{* *}$ & 1,29 & 0,00 \\
\hline Sementes $\mathrm{x}$ estádio & $25,71^{* *}$ & & 1,43 & 0,63 & 0,90 \\
\hline$\overline{\mathrm{CV}(\%)}$ & 31,61 & 27,52 & 17,63 & 2,85 & 18,36 \\
\hline
\end{tabular}

* e **Significativo a 5 e $1 \%$ de probabilidade, respectivamente, pelo teste F. ${ }^{(1)} \mathrm{QS}$, quantidade de sementes $\left(200,400,600,800\right.$ e 1.000 PVC). ${ }^{(2)} \mathrm{ED}$, estádio de desenvolvimento. 
aos 60 DAC. A interação entre quantidade de sementes e estádios de desenvolvimento foi significativa apenas para densidade de plantas aos 15 DAS. Todavia, os fatores isolados ou a interação deles não foram significativos quanto à matéria seca de plantas aos 233 DAC.

Ao desdobrar a interação entre quantidade de sementes e estádios de desenvolvimento, aos 15 DAS, os estádios de desenvolvimento da soja não diferiram entre si quando foram utilizadas 200 e 400 PVC de sementes (Tabela 2). Contudo, nas demais quantidades de sementes, houve maior número de plantas com a sobressemeadura no estádio $\mathrm{R}_{6}$ comparado ao $\mathrm{R}_{8}$. Além disso, em $\mathrm{R}_{6}$, a densidade de plantas aumentou linearmente com o acréscimo da quantidade de sementes (Figura 2 A). Para o estádio $R_{8}$, não houve diferença significativa entre as densidades de semeadura, e o valor médio foi de 0,92 plantas por $\mathrm{m}^{2}$.

Aos 35 DAS, nos dois estádios de desenvolvimento da soja, no momento da sobressemeadura, o número de plantas aumentou linearmente com o aumento da quantidade de sementes (Figura $2 \mathrm{~B}$ ), tendo-se obtido de 1,5 a 8,2 plantas por $\mathrm{m}^{2}$, nas quantidades de 200 a 1000 PVC de sementes. Kluthcouski \& Aidar (2003) recomendam o mínimo de 6 plantas por $\mathrm{m}^{2}$ das espécies de braquiária, para o estabelecimento como plantas de cobertura na região do Cerrado. No presente estudo, para obter essa densidade de plantas, seria necessária a sobressemeadura de 735 PVC de sementes. Silva et al. (2013), ao avaliar a sobressemeadura de 600 PVC de sementes de $B$. ruziziensis, no estádio $\mathrm{R}_{5.3}$ da cultura da soja, conseguiram de 5,5 a 13,5 plantas por $\mathrm{m}^{2}$, conforme o espaçamento das entrelinhas da soja.

Tabela 2. Densidade de plantas de Urochloa ruziziensis, em $5,4 \mathrm{~m}^{2}$, aos 15 dias após a sobressemeadura de diferentes quantidades de sementes, em dois estádios $\left(\mathrm{R}_{6} \mathrm{e} \mathrm{R}_{8}\right)$ de desenvolvimento da soja ${ }^{(1)}$.

\begin{tabular}{lcc}
\hline Quantidade de sementes & \multicolumn{2}{c}{ Estádios de desenvolvimento } \\
\cline { 2 - 3 } (PVC) & $\mathrm{R}_{6}$ & $\mathrm{R}_{8}$ \\
\hline 200 & $7,75 \mathrm{a}$ & $1,75 \mathrm{a}$ \\
400 & $13,00 \mathrm{a}$ & $5,25 \mathrm{a}$ \\
600 & $31,75 \mathrm{a}$ & $6,00 \mathrm{~b}$ \\
800 & $41,25 \mathrm{a}$ & $5,50 \mathrm{~b}$ \\
1000 & $61,00 \mathrm{a}$ & $6,25 \mathrm{~b}$ \\
\hline DMS (na linha) & \multicolumn{3}{c}{8,23} \\
\hline
\end{tabular}

${ }^{(1)}$ Médias seguidas de letras iguais nas linhas não diferem pelo teste de Tukey, a 5\% de probabilidade.
As condições meteorológicas, principalmente a ocorrência de chuvas antes da sobressemeadura e até dez dias após a emergência, são primordiais para o estabelecimento das plantas. A esse respeito, após a semeadura de $U$. ruziziensis em $\mathrm{R}_{6}$ e $\mathrm{R}_{8}$, a precipitação acumulada nos 20 dias seguintes foi de 107,6 e $31,6 \mathrm{~mm}$, respectivamente. Essa diferença de volumes de chuva influenciou a emergência inicial (primeiros 15 DAS) da forrageira sobressemeada no estádio $R_{8}$, em comparação à forrageira no $\mathrm{R}_{6}$. Porém, esse efeito não foi mais observado na segunda época de contagem (35 DAS), o que comprova que a emergência das plantas sobressemeadas em $\mathrm{R}_{8}$ foi mais lenta, mas normalizou-se com o decorrer do tempo.

Em relação à percentagem de cobertura do terreno pelas plantas de $U$. ruziziensis, o melhor ajuste dos dados foi obtido na forma polinomial, com maior média (74\%) a partir de 800 PVC, aos 60 DAC; e a oscilação dos valores foi de $92,3 \%$ (200 PVC) a 99,6\% (1.000 PVC), aos 233 DAC (Figura 2 C). Além disso, aos $60 \mathrm{DAC}$, quando a sobressemeadura foi realizada em $\mathrm{R}_{6}$, houve maior percentagem de cobertura $(65,0 \%)$ do que no estádio $R_{8}(47,8 \%)$. Em uma área onde a forrageira será utilizada para alimentação animal no outono-inverno, a sobressemeadura em $\mathrm{R}_{6}$ é a mais indicada, em razão do crescimento e da cobertura mais rápida do terreno. Porém, para o requisito único de formação de palha para o sistema plantio direto, os dois estádios mostraram-se promissores para a sobressemeadura da espécie forrageira, pois, aos 233 DAC não se observou diferença significativa entre os estádios quanto à percentagem de cobertura do terreno pela forrageira. Como a planta de U. ruziziensis é subereta e apresenta colmos geniculados na parte inferior da planta (Kissmann, 1997), mesmo nas parcelas com menor densidade de plantas a cobertura do terreno foi uniforme, com valores acima de $90 \%$.

Embora, aos 35 DAS, tenha-se constatado aumento linear do número de plantas de $U$. ruziziensis, com o aumento da quantidade de sementes, tal fato não se refletiu no acúmulo de massa aos 233 DAC. Possivelmente, nas parcelas com menor densidade de plantas, houve maior acúmulo de matéria seca por planta, o que representa uma compensação na produção de matéria seca por área. Além disso, a precipitação acumulada de 427,8 $\mathrm{mm}$ no outono-inverno (de março a setembro) foi suficiente para o desenvolvimento das plantas, tendo-se obtido excelente acúmulo de matéria seca. Portanto, apenas 200 PVC de sementes 
de $U$. ruziziensis, sobressemeadas nos estádios $R_{6}$ ou $\mathrm{R}_{8}$ da soja, foram suficientes para a manutenção de quantidade adequada de palha sobre o solo, com média de 16,2 $\mathrm{Mg} \mathrm{ha}^{-1}$. Em outros trabalhos, a sobressemeadura de $B$. ruziziensis, nos estádios $\mathrm{R}_{7}$ (768 PVC de sementes) e $\mathrm{R}_{5.5}$ (780 PVC de sementes) da soja, promoveu a manutenção de 7,2 e 10,8 $\mathrm{Mg} \mathrm{ha}^{-1}$ de palha sobre o solo, respectivamente, antes da semeadura da soja do próximo ano agrícola (Pacheco et al., 2008; Pacheco et al., 2013).

Houve efeito significativo da quantidade de sementes de $U$.ruziziensis sobre a percentagem de infestação de plantas daninhas, aos $233 \mathrm{DAC}$, que se reduziu com o aumento da quantidade de sementes de $U$. ruziziensis, com ajuste polinomial dos dados, e obteve nota zero a partir de 600 PVC (Figura 2 D). As outras variáveis avaliadas na comunidade infestante não foram afetadas pelos fatores isolados ou pela interação deles (Tabela 3).

Não houve variação expressiva da quantidade e homogeneidade de distribuição da palha de $U$. ruziziensis sobre o solo com o aumento da densidade de semeadura ou alteração da época de sobressemeadura. Esse resultado incidiu diretamente sobre a comunidade infestante, tanto antes quanto depois da semeadura do milho.

Por meio da análise de contrastes ortogonais, independentemente da densidade de semeadura e do estádio de desenvolvimento, os tratamentos com $U$. ruziziensis diferiram da testemunha sem
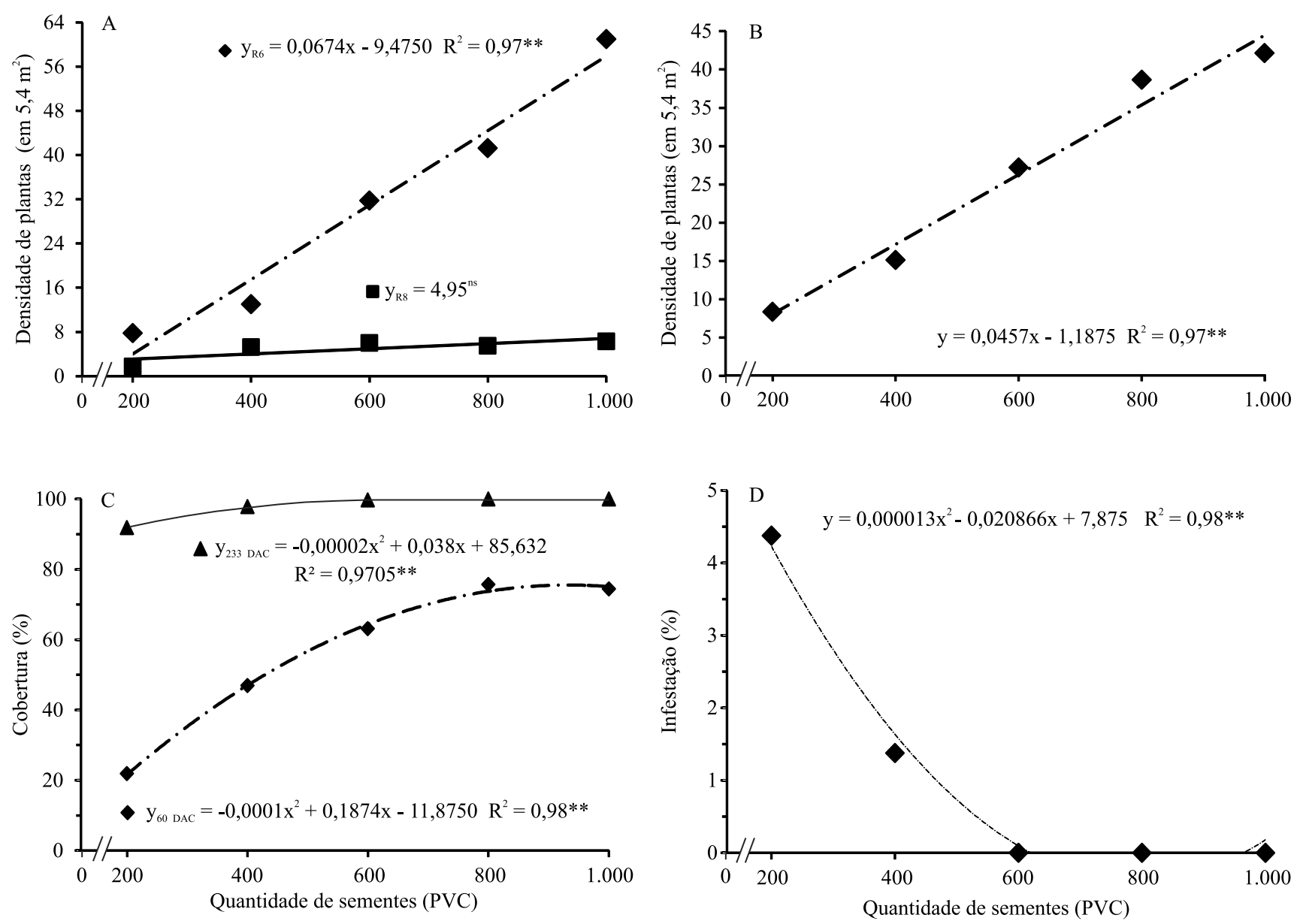

Figura 2. Densidade de plantas de Urochloa ruziziensis em $5,4 \mathrm{~m}^{2}$, aos 15 (A) e 35 (B) dias após a sobressemeadura (DAS) de diferentes quantidades de sementes, em dois estádios de desenvolvimento da soja $\left(\mathrm{R}_{6}\right.$ e $\left.\mathrm{R}_{8}\right)$; cobertura do terreno pelas plantas de Urochloa ruziziensis, aos 60 e 233 dias após a colheita (DAC) da soja (C); e infestação de plantas daninhas aos 233 DAC da soja (D). 
sobressemeadura e resultaram em menor infestação, densidade e matéria seca de plantas daninhas (Tabela 4). Ao comparar os tratamentos de sobressemeadura (valor médio) com a testemunha sem U. ruziziensis, houve redução de 91 e $97 \%$ da densidade e da matéria seca de plantas daninhas, respectivamente, aos 29 dias após a semeadura do milho. Pacheco et al. (2009) também verificaram que a sobressemeadura de $B$. decumbens, B. ruziziensis e $B$. brizantha, no estádio $\mathrm{R}_{7}$ da soja e em épocas mais precoces (janeiro ou fevereiro), foi uma importante ferramenta para o manejo integrado de plantas daninhas.

Experimentos de campo, com produção no local dos resíduos vegetais, são extremamente complexos, pois se trata da somatória do manejo adotado no período de outono-inverno, com a manutenção das culturas para produção de palha, e os efeitos propriamente ditos dessa palha depositada sobre o solo (Correia et al., 2013). Uma forma de reduzir a densidade populacional potencial de plantas daninhas, em determinada área, é evitar a adição de novos diásporos ao solo, conseguida, entre outros manejos, por meio do controle da produção de sementes pela planta, no período do outono-inverno. Esta prática é denominada de manejo na entressafra, e busca a eliminação das plantas daninhas, por meios químicos, mecânicos ou culturais, antes que elas produzam sementes (Correia et al., 2013).

Tabela 3. Resultados do teste F, quanto à percentagem de infestação de plantas daninhas aos 233 dias após a colheita (DAC) da soja, densidade e matéria seca da parte aérea de plantas daninhas, aos 29 dias após a semeadura (DAS) do milho, além de estande aos 23 e 122 dias após a semeadura (DAS) do milho, altura de plantas aos 66 DAS, número de espigas e produção de grãos de milho, em razão da sobressemeadura de diferentes quantidades de sementes de Urochloa ruziziensis, em dois estádios de desenvolvimento da soja.

\begin{tabular}{|c|c|c|c|c|c|c|c|c|}
\hline \multirow{2}{*}{$\begin{array}{l}\text { Fontes de } \\
\text { variação }\end{array}$} & \multirow{2}{*}{$\begin{array}{l}\text { Infestação } \\
233 \text { DAC }\end{array}$} & \multirow{2}{*}{$\begin{array}{c}\text { Densidade } \\
29 \text { DAS }\end{array}$} & \multirow{2}{*}{$\begin{array}{c}\text { Matéria seca } \\
29 \text { DAS }\end{array}$} & \multicolumn{2}{|c|}{ Estande } & \multirow{2}{*}{$\begin{array}{c}\text { Altura } \\
66 \text { DAS }\end{array}$} & \multirow{2}{*}{$\begin{array}{c}\text { Número de } \\
\text { espigas }\end{array}$} & \multirow{2}{*}{$\begin{array}{c}\text { Produtividade } \\
\text { de grãos }\end{array}$} \\
\hline & & & & $23 \mathrm{DAS}$ & $122 \mathrm{DAS}$ & & & \\
\hline Quantidade de sementes & $9,39 *$ & 1,39 & 1,90 & 2,37 & 1,94 & $3,86^{*}$ & 2,54 & 1,83 \\
\hline Estádio de desenvolvimento & 0,13 & 0,03 & 0,12 & 0,33 & 0,10 & $13,20 * *$ & 0,33 & 0,96 \\
\hline Sementes $\mathrm{x}$ estádio & 0,07 & 0,34 & 0,21 & 0,67 & 1,98 & 0,30 & 0,57 & 1,11 \\
\hline CV (\%) & 32,42 & 44,65 & 60,00 & 12,30 & 16,65 & 2,75 & 11,25 & 9,25 \\
\hline
\end{tabular}

* $\mathrm{e} * *$ Significativo a 5 e $1 \%$ de probabilidade, respectivamente, pelo teste $\mathrm{F}$.

Tabela 4. Resultados do teste F, por meio de contrastes ortogonais das quantidades de sementes $\mathrm{x}$ testemunha e dos estádios de desenvolvimento x testemunha, além dos valores médios da percentagem de infestação de plantas daninhas, aos 233 dias após a colheita (DAC) da soja, densidade e matéria seca da parte aérea de plantas aos 29 dias após a semeadura (DAS) do milho, além dos valores médios do estande aos 23 e 122 dias após a semeadura (DAS) do milho, altura de plantas aos 66 DAS, número de espigas e produtividade de grãos de milho, estabelecido em rotação à sobressemeadura de Urochloa ruziziensis na cultura da soja. ${ }^{(1)}$

\begin{tabular}{|c|c|c|c|c|c|c|c|c|}
\hline \multirow[t]{2}{*}{ Tratamento } & \multirow{2}{*}{$\begin{array}{c}\text { Infestação } \\
(\%)\end{array}$} & \multirow{2}{*}{$\begin{array}{l}\text { Densidade } \\
\left(\text { planta } \mathrm{m}^{-2}\right)\end{array}$} & \multirow{2}{*}{$\begin{array}{c}\text { Matéria seca } \\
\left(\mathrm{g} \mathrm{m}^{-2}\right)\end{array}$} & \multicolumn{2}{|c|}{ Estande (1.000 plantas ha $\left.{ }^{-1}\right)$} & \multirow{2}{*}{$\begin{array}{l}\text { Altura } \\
(\mathrm{cm})\end{array}$} & \multirow{2}{*}{$\begin{array}{l}\mathrm{N}^{\circ} \text { de espigas } \\
\left(1.000 \mathrm{ha}^{-1}\right)\end{array}$} & \multirow{2}{*}{$\begin{array}{l}\text { Produtividade } \\
\quad\left(\mathrm{kg} \mathrm{ha}^{-1}\right)\end{array}$} \\
\hline & & & & 23 DAS & $122 \mathrm{DAS}$ & & & \\
\hline \multicolumn{9}{|l|}{ Quantidade sementes (PVC) } \\
\hline 200 & $4,38 * *$ & $10,83 * *$ & $2,36^{* *}$ & 52,78 & 51,67 & 248,72 & 50,00 & $5.866^{*}$ \\
\hline 400 & $1,38 * *$ & $3,61 * *$ & $0,27 * *$ & 51,94 & 50,28 & 241,05 & 48,19 & $5.594 * *$ \\
\hline 600 & $0,00 * *$ & $4,16^{* *}$ & $0,37 * *$ & 45,28 & 44,86 & 241,58 & 42,92 & $5.403 * *$ \\
\hline 800 & $0,00 * *$ & $3,33 * *$ & $0,40 * *$ & 50,97 & 42,64 & 242,91 & 46,81 & $5.363 * *$ \\
\hline 1.000 & $0,00 * *$ & $1,94 * *$ & $0,22 * *$ & 46,81 & 45,28 & $235,79 *$ & 43,89 & $5.244 * *$ \\
\hline \multicolumn{9}{|l|}{ Estádio de desenvolvimento } \\
\hline $\mathrm{R}_{6}$ & $1,05^{* *}$ & $4,99 * *$ & $0,83 * *$ & 48,99 & 47,33 & 238,18 & 45,89 & $5.415 * *$ \\
\hline $\mathrm{R}_{8}$ & $1,25 * *$ & $4,55 * *$ & $0,62 * *$ & 50,11 & 46,56 & 245,84 & 46,83 & $5.573 * *$ \\
\hline Testemunha sem sobressemeadura & 42,50 & 55,00 & 22,18 & 55,28 & 54,44 & 243,63 & 51,94 & 6758 \\
\hline
\end{tabular}

(1)Médias seguidas de * e ** diferem da testemunha sem sobressemeadura, pelo teste $\mathrm{F}$ da análise por contrastes ortogonais, a 5 e $1 \%$ de probabilidade, respectivamente. 
No presente estudo, as plantas de $U$. ruziziensis cobriram o solo na entressafra, o que impediu a ocorrência de plantas daninhas, contrariamente ao observado na testemunha sem sobressemeadura. Nesta, houve altíssima infestação e produção de sementes pelas plantas daninhas, o que aumentou o banco de sementes do solo e, por conseguinte, o potencial de infestações futuras no local. Somada ao efeito da cobertura "verde" na entressafra, há a palha estabelecida sobre o solo após o manejo químico ("dessecação"), que pode afetar a emergência das plantas daninhas por três processos distintos: o físico, o biológico e o químico, com possíveis interações entre eles (Pitelli \& Durigan, 2001).

Não se observou diferença significativa entre as densidades de semeadura $\mathrm{e}$ as épocas de sobressemeadura no desenvolvimento do milho, exceto para altura de plantas aos 66 dias após a semeadura (Tabela 3). Isto pode ser justificado pela quantidade similar de palha produzida entre os tratamentos, além de sua distribuição uniforme sobre o terreno.

A altura das plantas de milho diminuiu linearmente com o aumento da quantidade de sementes de U. ruziziensis, e atingiu o menor valor com 1.000 PVC (Figura 3). Quando a sobressemeadura foi realizada em $\mathrm{R}_{8}$, as plantas de milho atingiram maior altura $(245,84 \mathrm{~cm})$ do que no estádio $\mathrm{R}_{6}(238,18 \mathrm{~cm})$.

Por meio da análise de contrastes ortogonais, independentemente da quantidade de sementes e do estádio de desenvolvimento, no momento da sobressemeadura, não houve diferença entre eles e a testemunha para estande aos 23 e 122 DAS, altura de plantas e número de espigas (Tabela 4), com exceção do tratamento 1.000 PVC, que resultou em plantas de menor altura. Todavia, houve maior produtividade de grãos de milho na testemunha sem sobressemeadura do que nos tratamentos com $U$. ruziziensis, com perda de $19 \%$ na produção, em média. Provavelmente, esse decréscimo da produção de grãos foi ocasionado pela densa camada de palha formada sobre o solo (16,2 $\left.\mathrm{Mg} \mathrm{ha}^{-1}\right)$, que resultou em efeitos químicos, como a alelopatia e a imobilização do $\mathrm{N}$ mineral pela microbiota do solo.

Durante o processo de decomposição dos resíduos vegetais, substâncias orgânicas denominadas aleloquímicos, podem ser lixiviadas pelas chuvas e, carreadas para a solução do solo, podem atingir concentrações suficientes para interferir negativamente nas plantas de interesse. Souza et al., 2006 relatam que a incorporação de palha de $B$. decumbens ao solo afetou drasticamente a quantidade de clorofila, a área foliar, e a matéria seca das folhas, do caule e das plantas de milho. A imobilização do $\mathrm{N}$ mineral pelos microrganismos do solo promove o esgotamento temporário desse nutriente no solo. Ainda que, posteriormente, com o declínio da população microbiana, os níveis de $\mathrm{N}$ sejam restabelecidos (Correia \& Durigan, 2006; Venzke Filho et al., 2008; Carneiro et al., 2013).

Quanto às análises foliares de nutrientes, houve efeito significativo das quantidades de sementes e dos estádios de desenvolvimento nos teores de P(Tabela 5). A interação entre quantidades de sementes e estádios não foi significativa para nenhum nutriente avaliado nas folhas de milho.
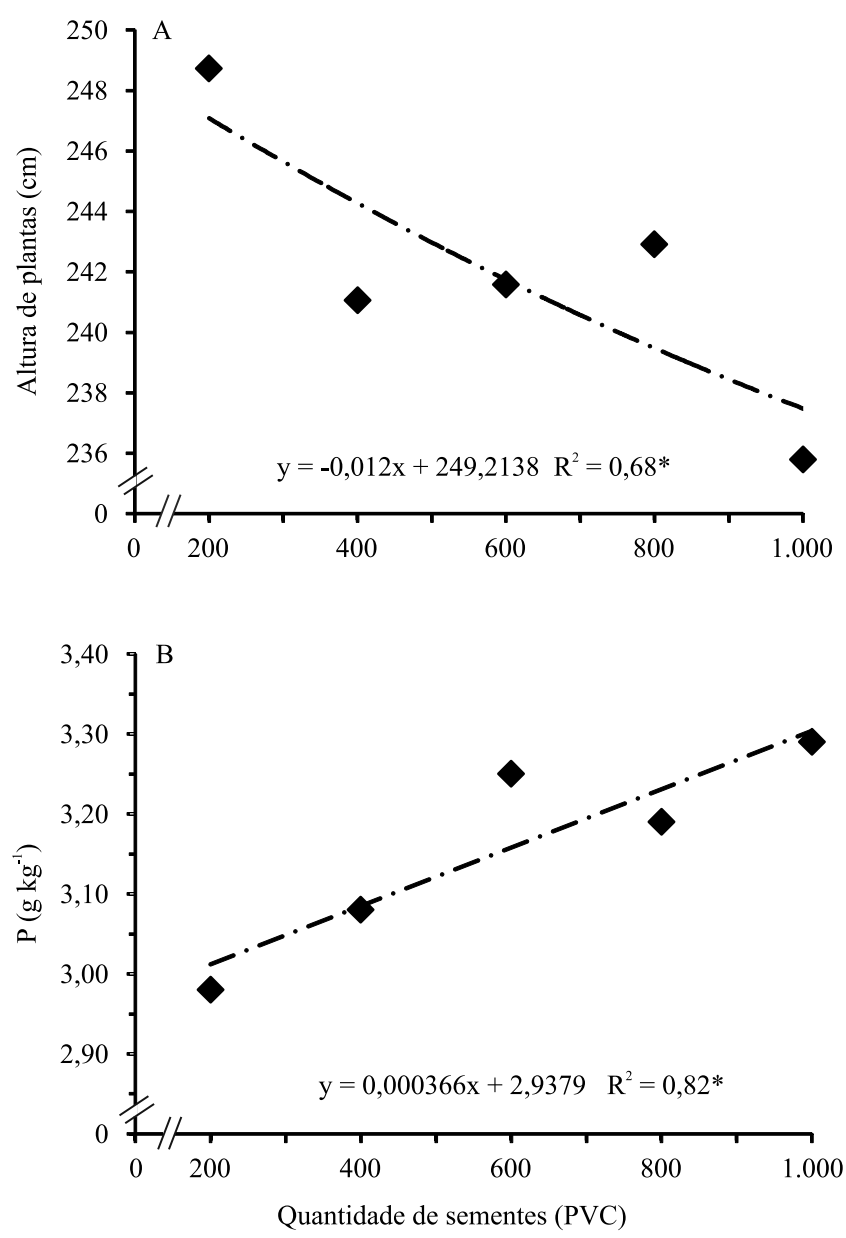

Figura 3. Altura de plantas de milho, aos 66 dias após a semeadura, e teores de $\mathrm{P}$ em folhas de milho, estabelecido em rotação à sobressemeadura de diferentes quantidades de sementes de Urochloa ruziziensis na cultura da soja. 
Tabela 5. Resultados do teste $\mathrm{F}$ da análise de variância e por meio de contrastes ortogonais quanto aos teores de N, P, K, $\mathrm{Ca}, \mathrm{Mg}, \mathrm{S}, \mathrm{B}, \mathrm{Cu}, \mathrm{Fe}, \mathrm{Mn}$ e Zn, em folhas de milho estabelecido em rotação à sobressemeadura de diferentes quantidades de sementes de Urochloa ruziziensis, em dois estádios de desenvolvimento da soja.

\begin{tabular}{|c|c|c|c|c|c|c|c|c|c|c|c|}
\hline Fonte de variação & $\mathrm{N}$ & $P$ & $\mathrm{~K}$ & $\mathrm{Ca}$ & $\mathrm{Mg}$ & $\mathrm{S}$ & $\mathrm{B}$ & $\mathrm{Cu}$ & $\mathrm{Fe}$ & $\mathrm{Mn}$ & $\mathrm{Zn}$ \\
\hline & \multicolumn{11}{|c|}{ Análise de variância ${ }^{(1)}$} \\
\hline Quantidade de sementes & 0,62 & $3,41^{*}$ & 0,32 & 0,16 & 1,13 & 1,25 & 0,62 & 0,72 & 0,32 & 0,17 & 0,75 \\
\hline Estádio de desenvolvimento & 1,20 & $6,90 *$ & 0,92 & 0,45 & 0,31 & 0,03 & 0,18 & 0,00 & 0,17 & 0,58 & 3,29 \\
\hline Sementes $\mathrm{x}$ estádio & 0,10 & 3,00 & 0,28 & 0,58 & 0,86 & 0,84 & 1,33 & 0,48 & 0,80 & 1,17 & 2,32 \\
\hline \multirow[t]{2}{*}{$\mathrm{CV}(\%)$} & 7,74 & 6,20 & 3,90 & 9,46 & 9,35 & 9,22 & 11,44 & 11,79 & 14,38 & 12,28 & 9,12 \\
\hline & \multicolumn{11}{|c|}{ Análise por meio de contrastes ortogonais ${ }^{(2)}$} \\
\hline \multicolumn{12}{|l|}{ Quantidade de sementes (PVC) } \\
\hline 200 & 22,38 & 2,98 & 22,00 & 3,38 & 2,23 & 1,29 & 5,15 & 8,88 & 111,12 & 30,62 & 30,62 \\
\hline 400 & 22,21 & $3,08^{*}$ & 22,25 & 3,39 & 2,14 & 1,24 & 4,82 & 8,88 & 112,12 & 30,62 & 30,62 \\
\hline 600 & 23,25 & $3,25^{* *}$ & 22,12 & 3,39 & 2,16 & 1,36 & 5,11 & 9,50 & 113,25 & 29,38 & 29,38 \\
\hline 800 & 22,10 & $3,19 * *$ & 22,44 & 3,29 & 2,06 & 1,33 & 4,89 & 9,00 & 119,00 & 30,25 & 30,25 \\
\hline 1.000 & 22,89 & $3,29 * *$ & 22,34 & 3,32 & 2,05 & 1,31 & 4,84 & 9,50 & 116,62 & 30,62 & 30,62 \\
\hline \multicolumn{12}{|l|}{ Estádio de desenvolvimento } \\
\hline $\mathrm{R}_{6}$ & 22,87 & $3,24 * *$ & 22,36 & 3,32 & 2,11 & 1,30 & 4,92 & 9,15 & 115,50 & 29,85 & 29,85 \\
\hline $\mathrm{R}_{8}$ & 22,26 & $3,08^{*}$ & 22,10 & 3,39 & 2,15 & 1,31 & 5,00 & 9,15 & 113,35 & 30,75 & 30,75 \\
\hline Testemunha sem sobressemeadura & 22,05 & 2,82 & 21,38 & 3,45 & 2,06 & 1,29 & 4,88 & 9,25 & 120,75 & 32,50 & 32,50 \\
\hline
\end{tabular}

(1)* e **Significativo a 5 e $1 \%$ de probabilidade, respectivamente, pelo teste $\mathrm{F} .{ }^{(2)}$ Médias seguidas de $* \mathrm{e} * *$ diferem da testemunha sem sobressemeadura, pelo teste $\mathrm{F}$ da análise por contrastes ortogonais, a 5 e $1 \%$ de probabilidade, respectivamente.

Os teores de $\mathrm{P}$ nas folhas de milho aumentaram linearmente como acréscimo da densidade de semeadura de $U$. ruziziensis, com acréscimo de $36,6 \mathrm{mg} \mathrm{kg}^{-1}$ a cada 100 PVC de sementes (Figura 3). Além disso, as plantas de milho estabelecidas nas parcelas do estádio $\mathrm{R}_{6}$ apresentaram maior concentração de $\mathrm{P}$ $\left(3,24 \mathrm{~g} \mathrm{~kg}^{-1}\right)$ nas folhas do que as plantas das parcelas do estádio $\mathrm{R}_{8}\left(3,08 \mathrm{~g} \mathrm{~kg}^{-1}\right)$. Nesse sentido, Pacheco et al. (2013) relataram o acúmulo de $\mathrm{N}, \mathrm{P}$ e K pelas plantas de $U$. ruziziensis, que é importante na ciclagem desses nutrientes e para a disponibilidade a culturas sucessoras. Merlin et al., 2013 relatam que o cultivo de $U$. ruziziensis aumentou os teores de $\mathrm{P}$ no solo, assim como o seu conteúdo nas folhas da soja que sucedeu a forrageira.

Por contrastes, os tratamentos com $U$. ruziziensis diferiram da testemunha sem sobressemeadura apenas para $\mathrm{P}$ nas folhas (Tabela 5). As plantas de milho dos tratamentos de sobressemeadura, exceto para a quantidade $200 \mathrm{PVC}$, apresentaram maior teor de $\mathrm{P}$ do que as plantas da testemunha. Para os outros nutrientes avaliados, não houve diferença significativa entre os tratamentos de sobressemeadura e a testemunha. Esses resultados corroboram a hipótese de que o decréscimo da produção de grãos de milho, nas parcelas com palha de $U$. ruziziensis, originou-se do efeito alelopático da própria palha e não de distúrbio nutricional.

\section{Conclusões}

1. A sobressemeadura de 200 PVC de Urochloa ruziziensis, nos estádios $\mathrm{R}_{6}$ ou $\mathrm{R}_{8}$ da soja, resulta na formação de palha em quantidade suficiente para o sistema plantio direto, além de beneficiar o controle de plantas daninhas na cultura do milho em rotação.

2. Em quantidade elevada $\left(16,2 \mathrm{Mg} \mathrm{ha}^{-1}\right)$, a palha de $U$. ruziziensis sobre o solo afeta a altura de plantas e a produtividade de grãos de milho em rotação.

\section{Agradecimentos}

À Fundação de Amparo à Pesquisa do Estado de São Paulo (Fapesp, processo número 2010/18286-0), pelo apoio financeiro.

\section{Referências}

BARDUCCI, R.S.; COSTA, C.; CRUSCIOL, C.A.C.; BORGHI, É.; PUTAROV, T.C.; SARTI, L.M.N. Produção de Brachiaria brizantha e Panicum maximum com milho e adubação nitrogenada. 
Archivos de Zootecnia, v.58, p.211-222, 2009. DOI: 10.4321/ s0004-05922009000200006.

CARNEIRO, W.J. de O.; SILVA, C.A.; MUNIZ, J.A.; SAVIAN, T.V. Mineralização de nitrogênio em latossolos adubados com resíduos orgânicos. Revista Brasileira de Ciência do Solo, v.37, p.715-725, 2013. DOI: 10.1590/S0100-06832013000300018.

CORREIA, N.M.; DURIGAN, J.C. Influência do tipo e da quantidade de resíduos vegetais associados a herbicidas residuais no desenvolvimento da cultura da soja. Bragantia, v.65, p.421-432, 2006. DOI: $10.1590 / \mathrm{S} 0006-87052006000300008$.

CORREIA, N.M.; LEITE, M.B.; FUZITA, W.E. Consórcio de milho com Urochloa ruziziensis e os efeitos na cultura da soja em rotação. Bioscience Journal, v.29, p.65-76, 2013.

ESTAÇÃO agroclimatológica: estação convencional: dados meteorológicos mensais. Jaboticabal: Faculdade de Ciências Agrárias e Veterinárias, Unesp, [2015]. Disponível em: <http:// www.fcav.unesp.br/\#!/estacao-agroclimatologica/dados/ estacao-convencional/>. Acesso em: 23 mar. 2015.

KISSMANN, K.G. Plantas infestantes nocivas. 2.ed. São Paulo: Basf, 1997. 825p.

KLUTHCOUSKI, J.; AIDAR, H. Implantação, condução e resultados obtidos com o Sistema Santa Fé. In: KLUTHCOUSKI, J.; STONE, L.F.; AIDAR, H. (Ed.). Integração lavoura-pecuária. Santo Antônio de Goiás: Embrapa Arroz e Feijão, 2003. p.407-442.

LARA-CABEZAS, W.A.R. Sobressemeadura com sementes de milheto revestidas no Triângulo Mineiro-MG: estudo preliminar. Revista Plantio Direto, v.79, p.16-18, 2004.

MERLIN, A.; HE, Z.L.L.; ROSOLEM, C.A. Ruzigrass affecting soil-phosphorus availability. Pesquisa Agropecuária Brasileira, v.48, p.1583-1588, 2013. DOI: 10.1590/ S0100-204X2013001200007.

MIRANDA, M.J. de; PINTO, H.S.; ZULLO JÚNIOR, J.; FAGUNDES, R.M.; FONSECHI, D.B.; CALVE, L.; PELLEGRINO, G.Q. Clima dos municípios paulistas: a classificação climática de Koeppen para o Estado de São Paulo. Disponível em: <http:/www.cpa.unicamp.br/outras-informacoes/ clima-dos-municipios-paulistas.html $>$. Acesso em: 18 ago. 2015.

PACHECO, L.P.; PIRES, F.R.; MONTEIRO, F.P.; PROCÓPIO, S. de O.; ASSIS, R.L. de; CARMO, M.L. do; PETTER, F.A. Desempenho de plantas de cobertura em sobressemeadura na cultura da soja. Pesquisa Agropecuária Brasileira, v.43, p.815-823, 2008. DOI: 10.1590/S0100-204X2008000700005.

PACHECO, L.P.; PIRES, F.R.; MONTEIRO, F.P.; PROCÓPIO, S.O.; ASSIS, R.L.; CARGNELUTTI FILHO, A.; CARMO, M.L.; PETTER, F.A. Sobressemeadura da soja como técnica para supressão da emergência de plantas daninhas. Planta Daninha, v.27, p.455-463, 2009. DOI: 10.1590/ S0100-83582009000300005.

PACHECO, L.P.; MONTEIRO, M.M. de S.; SILVA, R.F. da; SOARES, L. dos S.; FONSECA, W.L.; NÓBREGA, J.C.A.; PETTER, F.A.; ALCÂNTARA NETO, F. de; OSAJIMA, J.A. Produção de fitomassa e acúmulo de nutrientes por plantas de cobertura no Cerrado piauiense. Bragantia, v.72, p.237-246, 2013. DOI: $10.1590 /$ brag.2013.041.

PERIN, A.; SANTOS, R.H.S.; URQUIAGA, S.; GUERRA, J.G.M.; CECON, P.R. Produção de fitomassa, acúmulo de nutrientes e fixação biológica de nitrogênio por adubos verdes em cultivo isolado e consorciado. Pesquisa Agropecuária Brasileira, v.39, p.35-40, 2004. DOI: 10.1590/S0100-204X2004000100005.

PITELLI, R.A.; DURIGAN, J.C. Ecologia das plantas daninhas no sistema de plantio direto. In: ROSSELLO, R.D. (Coord.). Siembra directa en el Cono Sur. Montevideo: Procisur, 2001. p.203-210.

SILVA, A.C. da; FREITAS, F.C.; FERREIRA, L.R.; FREITAS, R.S. Dessecação pré-colheita de soja e Brachiaria brizantha consorciadas com doses reduzidas de graminicida. Pesquisa Agropecuária Brasileira, v.41, p.37-42, 2006. DOI: 10.1590/ S0100-204X2006000100006.

SILVA, W.B.; PETTER, F.A.; LIMA, L.B. de; ANDRADE, F.R. Desenvolvimento inicial de Urochloa ruziziensis e desempenho agronômico da soja em diferentes arranjos espaciais no cerrado Mato-Grossense. Bragantia, v.72, p.146-153, 2013. DOI: 10.1590/ S0006-87052013000200006.

SOUZA, L.S.; VELINI, E.D.; MARTINS, D.; ROSOLEM, C.A. Efeito alelopático de capim-braquiária (Brachiaria decumbens) sobre o crescimento inicial de sete espécies de plantas cultivadas. Planta Daninha, v.24, p.657-668, 2006. DOI: 10.1590/ S0100-83582006000400006.

VENZKE FILHO, S. de P.; FEIGL, B.J.; PICCOLO, M. de C.; SIQUEIRA NETO, M.; CERRI, C.C. Biomassa microbiana do solo em sistema de plantio direto na região de Campos Gerais - Tibagi, PR. Revista Brasileira de Ciência do Solo, v.32, p.599-610, 2008. DOI: $10.1590 /$ S0100-06832008000200015.

Recebido em 20 de janeiro de 2015 e aprovado em 30 de agosto de 2015 